\title{
Biomechanical Properties of Fixed Liver
}

\author{
Yubin Zheng, Wu Zheng ${ }^{*}$, Yanli Wang and Feng Wang \\ School of Mechanical Science and Engineering, Jilin University, Changchun, 130000, China \\ ${ }^{*}$ Corresponding author
}

\begin{abstract}
Pathologic sampling is the initial stage of the pathological research and forensic identification, if the thickness of samplings can not meet the requirements, observation results will be affected, resulting in a higher rate of misdiagnosis. This paper aims at studying the biomechanical properties of fixed liver, and utilized SHIMADZU universal tensile testing machine to perform tension test at various loading rates $(0.5,1,5,10 \mathrm{~mm} / \mathrm{s})$. On this basis, drawing the mean stress-strain curves, and computing standard deviation. With loading rate increasing, the failure stresses increased from $74 \mathrm{KPa}$ to $101 \mathrm{KPa}$, and the failure strains were about 0.1 .
\end{abstract}

Keywords-pathological drawn; fixed liver; biomechanical properties; tension test

\section{INTRODUCTION}

Liver tissue is a kind of complex material, and its biomechanical properties will be affected by many factors, such as composition, content and distribution. The studies of fixed liver are helpful to construct constitutive model and provide theoretical data for medical workers and researchers. On the other hand, those researches also promote the development of finite element simulation [1]. At present, there are some studies on the fresh liver [2-5], but the research on the biomechanical properties of fixed liver are not common. This paper mainly studies the fixed liver at different loading rates for the analysis of biomechanical properties, and provides a basis for subsequence analysis.

\section{SPECIMEN PREPARATION}

Research has shown that the structure of ox liver and human liver are very similar [6], showing similar biomechanical properties. In view of the particularity of obtaining of human liver, this paper utilized ox liver to perform biomechanical test.

The process of specimen preparation should make the samples to meet the requirements of the test, including avoiding damage to the sample, and taking some measures to reduce the loss of water. So that, this paper utilized $10 \%$ formaldehyde solution to fix the samples.

At first, we bought 6 fresh bovine livers from slaughterhouse, and the liver tissues should be fixed in $10 \%$ formaldehyde solution for a week. Then selected samples. On the surface of liver, there are a layer of dense connective tissues that should be removed [7]. This paper selected 60 test samples in total, and the samples were sampled along the sagittal direction of the liver lobes. The sample shape and size are shown in Figure I.

\section{TEST EQUIPMENT}

As shown in Figure II, this paper utilized SHIMADZU universal tensile testing machine to perform tension test, and the effective pull force is in the range of $0.1 \sim 1000 \mathrm{~N}$. This equipment equips with load sensor and photoelectric coding sensor, and it is able to carry out tensile test, shear stress test, uniaxial tension or compression test.

Before the test, the data, including the sample size and material should be input into the program. And experimental data and curve are shown on the screen.
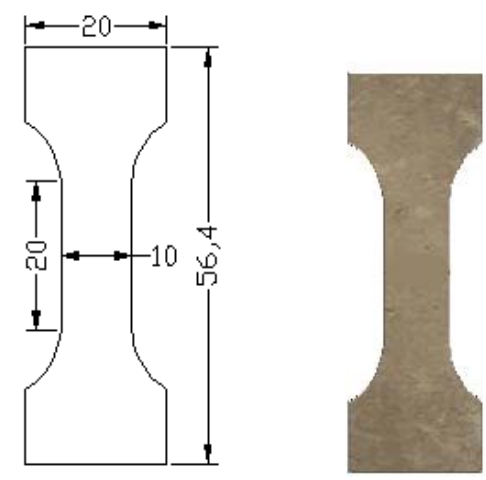

FIGURE I. SAMPLE SHAPE AND SIZE

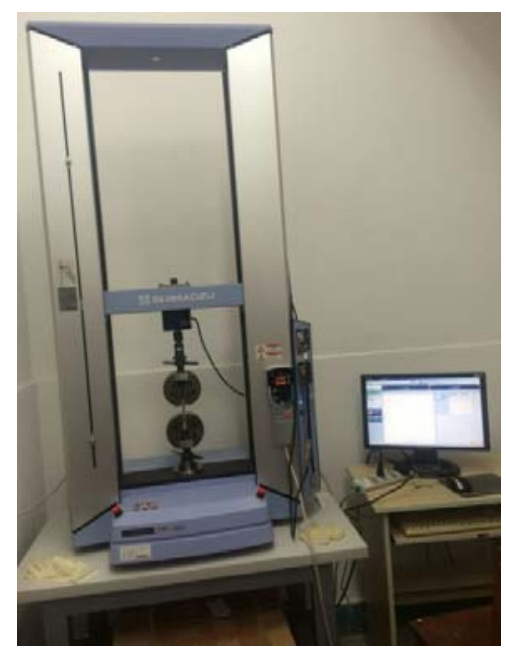

FIGURE II. EXPERIMENTAL DEVICE 


\section{TEST PROCEDURE}

Under the conditions of normal temperature and static load, uniaxial tensile test can measure many kinds of elastic parameter of samples, such as poisson's ratio, elastic modulus, yield strength, tensile strength, and so on. The experiment is convenient for data acquisition and analysis, and it is the most widely used measurement technology at present. In this paper, samples from the 6 bovine livers are conducted for tensile test. The maximum load of the preconditioning is $25 \% \sim 30 \%$ of the failure load. Before starting the test, the samples need to carry out repeated loading and unloading at the same rate for 20 times, so that the mechanical properties of the samples can reach the steady state. In order to study the rate dependence of liver tissues, each sample should perform tension test at various loading rates $(0.5,1,5,10 \mathrm{~mm} / \mathrm{s})$ [8]. The process of stretching is shown in Figure III.

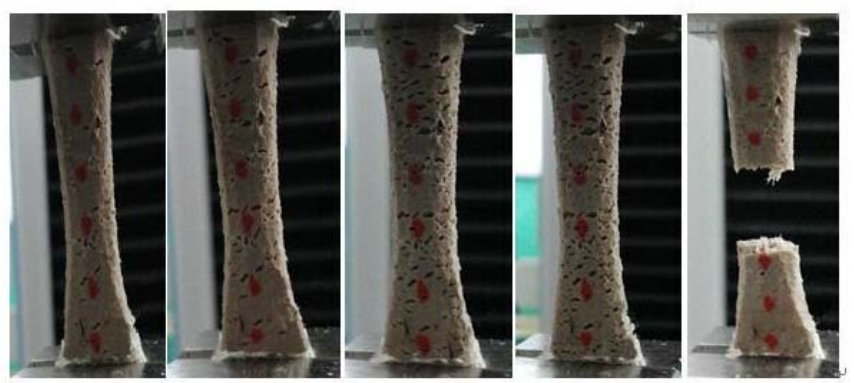

FIGURE III. UNIAXIAL TENSILE TEST

The stretch curves will be displayed on the screen in real time. There is a peak load before the tensile failure, and the failure point appears at the moment that peak load is decreased obviously. Based on the obtained tension-displacement curves, the stretch rate $(\lambda)$, strain $(\varepsilon)$ and failure stress $(\sigma)$ can be obtained according to the formula 1,2 and 3 .

$$
\begin{gathered}
\lambda=\frac{x_{n}}{L_{0}} \\
\varepsilon=\frac{1}{2}\left(\lambda^{2}-1\right) \\
\sigma=\frac{z}{8}
\end{gathered}
$$

where $\mathrm{L}_{\mathrm{n}}$-The length of the sample in the process of stretching;

$\mathbf{L}_{0} \_$The initial length of the sample;

$\mathrm{F}$ — Tensile force; $\mathrm{S}$ - Cross-sectional area of the sample.

The average stress-strain curve and standard deviation can be obtained based on the method used by Lessley. Then assuming that variance is not equal to carry out 2-Independent-Samples T Test, which is able to identify the significant of failure stress, failure strain and stretch rate. The significance level $(\mathrm{P})$ of this paper is less than 0.05 .

\section{TEST REsult}

This paper carried out 60 uniaxial tension tests at 4 loading rates, and drew 4 stress-strain curves based on experimental data. These curves help to identify the changes and average value of stress and strain during the test process. As shown in figure IV, V, VI and VII, the tensile processes of liver tissue at different tensile rates are nonlinear. And average maximum stress, maximum strain and strain rate at each loading rate can be obtained through a series of calculation. A summary of the results is shown in Table I.

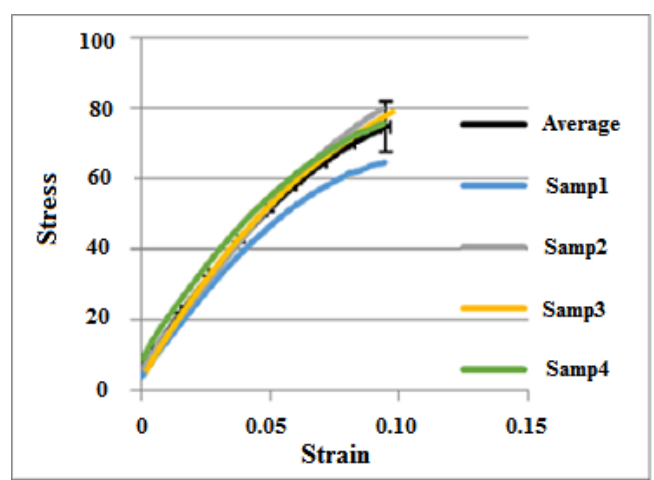

FIGURE IV. STRESS-STRAIN CURVES OF 0.5MM/S

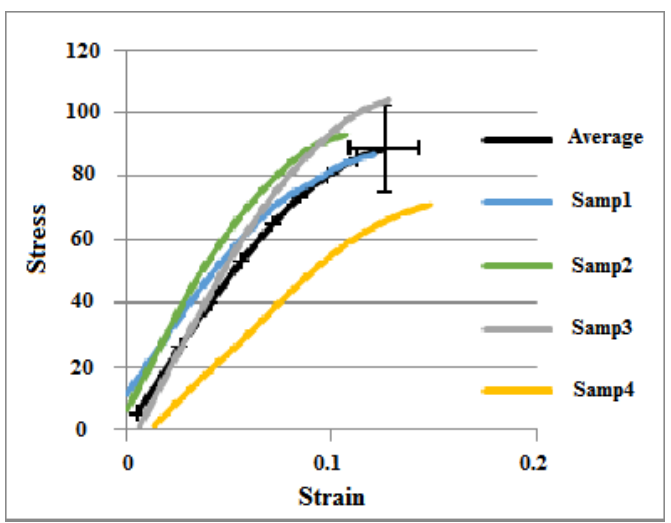

FIGURE V. STRESS-STRAIN CURVES OF 1MM/S

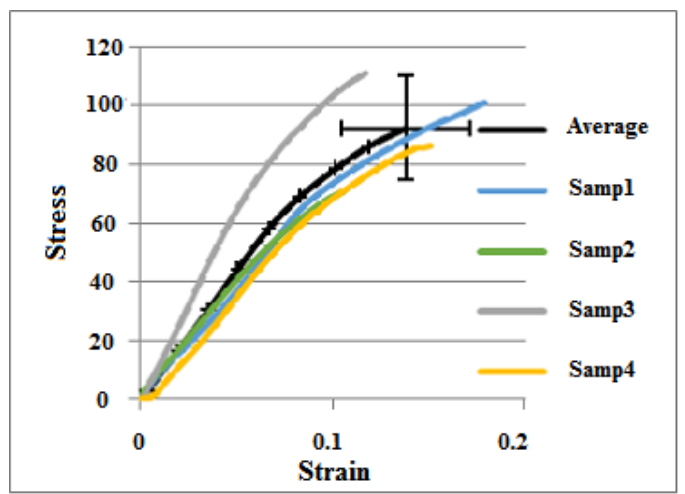

FIGURE VI. STRESS-STRAIN CURVES OF 5MM/S 


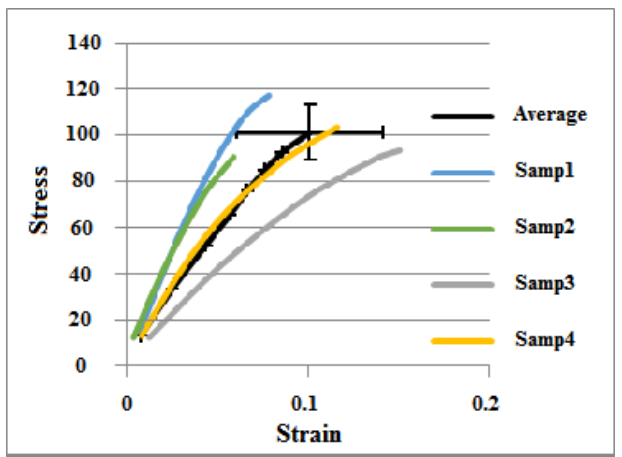

FIGURE VII. STRESS-STRAIN CURVES OF 10MM/S

TABLE I. AVERAGES AND STANDARD DEVIATIONS OF FAILURE STRESS AND FAILURE STRAIN

\begin{tabular}{|l|l|l|l|}
\hline $\begin{array}{c}\text { Rate } \\
\left(\mathbf{s}^{\mathbf{- 1}} \mathbf{)}\right.\end{array}$ & $\begin{array}{c}\text { Average } \\
\text { Loading Rate } \\
\left(\mathbf{s}^{\mathbf{- 1}}\right)\end{array}$ & $\begin{array}{c}\text { Average Failure } \\
\text { Stress } \\
\mathbf{( K p a )}\end{array}$ & $\begin{array}{c}\text { Average Failure } \\
\text { Strain }\end{array}$ \\
\hline 0.5 & $0.498( \pm 0.001)$ & $74.881( \pm 7.072)$ & $0.095( \pm 0.002)$ \\
1 & $0.989( \pm 0.013)$ & $88.943( \pm 13.833)$ & $0.125( \pm 0.017)$ \\
5 & $4.687( \pm 0.034)$ & $92.285( \pm 17.695)$ & $0.138( \pm 0.033)$ \\
10 & $9.589( \pm 1.324)$ & $101.091( \pm 11.981)$ & $0.101( \pm 0.041)$ \\
\hline
\end{tabular}

Result shows that the change of stress and strain of liver tissue is related to the tensile rate, and average failure stress increases obviously as the loading rate increases, increasing from $74 \mathrm{KPa}$ to $101 \mathrm{Kpa}$. And the failure strains were about 0.1 , there was no significant change in the average failure strain.

\section{CONCLUSIONS}

After the liver tissues were fixed and sampled, this paper carried out uniaxial tensile test at different loading rates $(0.5,1$, $5,10 \mathrm{~mm} / \mathrm{s}$ ), and got the stress- strain curves and the corresponding mechanical parameters. Results shows that:

(1) the failure stress of liver tissues exhibit nonlinear hysteresis during the stretching process, and with the increase of the tensile rate, the failure stress becomes more and more large;

(2) the change of failure strain is not obvious.

Although studies have shown that the structure and biomechanical properties of ox liver and human liver are very similar, but there are still some differences between them, so that, subsequent articles will study on the biomechanical properties of the human liver.

\section{ACKNOWLEDGEMENT}

This research was financially supported by the "Jilin Province Science and Technology Key Projects" of China (No. 20140204065SF).

\section{REFERENCES}

[1] Costin D, Untaroiu, Yuan-Chiao Lu. Material characterization of liver parenchyma using specimen-specific finite element models [J].Journal of the Mechanical Behavior of Biomedical Materials, 2003, 26:11-26.

[2] Sparks Jessica L, Bolte John H, Dupaix Rebecca B. Using pressure to predict liver injury risk from blunt impact[J]. Stapp Car Crash Journal, 2008, 51:401-405.
[3] Kemper Andrew R, McNally Craig, Pullins Clayton A. The biomechanics of human ribs: material and structural properties from dynamic tension and bending tests [J]. Stapp Car Crash Journal, 2008, 51:235-239.

[4] G. Mattei, A. Tirella, G. Gallone, A. Ahuluwalia. Viscoelastic characterization of pig liver in unconfined compression [J]. Journal of Biomechanics, 2014, 47(11):2641-2646.

[5] Tamura Atsutaka, Omori Kiyoshi, Miki Kazuo. Mechanical characterization of porcine abdominal organs [J]. Stapp Car Crash Journal, 2006, 46:55-60.

[6] Andrew R, Anthony C, Joel D, Jessica L. Biomechanical Response of Human Liver in Tensile Loading [J].Annals of advances in automotive medicine, 2010, 54:15-26.

[7] Stingl J, Baca V, Cech P. Morphology and some biomechanical properties of human liver and spleen [J]. Surgical and Radiological Anatomy, 2002, 24(5):285-289.

[8] Kemper Andrew R, Santago Anthony C, Stitzel Joel D. Biomechanical response of human liver in tensile loading $[\mathrm{J}]$. Annals of advances in automotive medicine, 2010, $54: 15-26$. 